\title{
DCCMP Regimen
}

National Cancer Institute

\section{Source}

National Cancer Institute. DCCMP Regimen. NCI Thesaurus. Code C161961.

A chemotherapy regimen consisting of daunorubicin, cyclocytidine, 6-mercaptopurine, and prednisone that may be used in the treatment of acute myeloid leukemia (AML). 